\title{
DEMOGRAPHIC APPROACH TO THE PROBLEM OF THE \\ CONNEXION BETWEEN LUNG CANCER AND SMOKING
}

\author{
BY \\ J. R. RELE \\ Department of Preventive and Social Medicine, Topiwala National Medical College, Bombay, India
}

To such as seek to examine the question whether there exists a demonstrable connexion between the prevalence of the smoking habit and the incidence of lung cancer, the City of Bombay has much of interest to offer. Embedded in its vast population is an ethno-cultural isolate, the Parsis, easily distinguished from the rest of the people by a number of differences, among the more striking of these being that, on religious grounds, they do not smoke.

The Parsis constitute a closed community. Their ethnic roots are not the same as those of the rest of Bombay's population. It is possible that, as a result of their long-continued, self-imposed segregation, they have come to differ genetically from the rest. Their culture differs markedly from the other groups which together with the Parsis constitute the population. Their standard of living is much higher, and they exhibit some demographic attributes more akin to those of advanced countries in the West. Of particular interest is the comparatively greater age of their population as a result of their lower mortality and lower fertility. Within their community medical care and the charitable succour of the needy are well organized.

The rest of the population, who may be described as non-Parsis, include adherents to a variety of other religious faiths. Though differing among themselves in this respect, they have many attributes in common, as far as considerations of mortality and living standards are concerned, and for the purposes of this study may be regarded as a homogeneous group that can fairly be used for comparison with the Parsis.
Though Parsis, as a community, do not smoke, it may be that a few of the younger males among them have latterly adopted the cigarette habit. This is a matter that can be disregarded in so far as this study is concerned with cancer mortality, since cancer is predominantly a disease of the old. Also "the rest" embraces sub-groups, whose members, for the same reasons as the Parsis, do not smoke; and even within the sub-groups where smoking is not prohibited, obviously not all members smoke. Nevertheless, the two main groups, Parsis and the rest, do differ markedly in respect of the proportion of their members who smoke; the Parsis can therefore be regarded as non-smokers and the rest as smokers.

The purpose of this study is to contrast the mortality from cancer (all sites) and from cancer of the lung among the Parsis and the rest. In this respect the present approach differs from that usually adopted, whereby case histories of the smoking habits of hospital patients form the basis of study and the nature and extent of selectivity is very often unknown.

The system of registration of births and deaths in Bombay city is among the best in India. The registration of deaths especially has been nearly complete, and the causes of death are classified according to the 200 causes given in the detailed International List of 1938. The city has more than its share of medical practitioners and is well supplied with hospitals. The presence within its boundaries of the Tata Memorial Hospital for Cancer and the Indian Cancer Research Centre ensures that interest in the subject of malignancy is lively and widespread and 
that diagnostic facilities are readily available. Consequently, a high index of "suspicion" is exercised in assigning the cause of death by both the hospital and the practitioner.

The data on deaths from cancer in Bombay city and suburbs in the years 1957 and 1958 were collected from the death records maintained by the Health Department of the Bombay Municipal Corporation $(1958,1959)$. The records of two years rather than one were taken tecause it was thought that the number of deaths from cancer of the lung in the Parsis might prove to be very small. This involved scanning some 80,000 death records, which gave particulars of the cause of death, sex, and religious faith of the deceased. There were discovered 63 male and 76 female deaths from cancer among the Parsis and 1,007 male and 519 female deaths from cancer among the rest. On the assumption that the number of Parsis in Bombay was 70,000 in 1957-58 and that of the rest $3,500,000$, the crude cancer mortality rate per 100,000 population per annum was as follows:

\begin{tabular}{c|c|c}
\hline Sex & Parsis & The Rest \\
\hline Male & 90 & 23 \\
Female & 109 & 20 \\
\hline
\end{tabular}

Thus it would appear that, on the basis of crude rates, mortality from cancer was much higher among the Parsis than among the rest, for both sexes.
Because of the connexion between the incidence of cancer and the age of the population at risk, an attempt was then made to examine the cancer death rates specific for age and sex. Unfortunately the age distribution of Parsis in the Bombay population is not recorded. That of the rest can be approximated by the city's age distribution at the 1951 census. Chandra Sekar (1948) gives a projected age distribution for Parsis in India in 1961, based on the 1931 census. This was assumed to be true for the Parsi population in Bombay, because of the similarity in the age distribution of Parsis in Bombay city and in the whole of India at the 1931 census. The comparative age distributions per cent. for Parsis and the rest according to these assumptions are presented in Table I.

TABLE I

PERCENTAGE AGE DISTRIBUTION OF PARSIS AND THE REST, BY SEX

\begin{tabular}{|c|c|c|c|c|c|}
\hline \multirow{2}{*}{$\frac{\text { Sex }}{\text { Population }}$} & \multirow{2}{*}{. } & \multicolumn{2}{|c|}{ Male } & \multicolumn{2}{|c|}{ Female } \\
\hline & & The Rest & Parsis & The Rest & Parsis \\
\hline \multirow[t]{2}{*}{$\begin{array}{c}\text { Age } \\
\text { (yrs) }\end{array}$} & $\begin{array}{l}<30 \\
30- \\
40- \\
50- \\
60- \\
70+\end{array}$ & $\begin{array}{r}61.7 \\
19.5 \\
10.9 \\
5.5 \\
1.8 \\
0.6\end{array}$ & $\begin{array}{r}42.5 \\
15.6 \\
15.3 \\
13.0 \\
8.1 \\
5.3\end{array}$ & $\begin{array}{r}69 \cdot 1 \\
14.0 \\
8.4 \\
4.7 \\
2.6 \\
1.1\end{array}$ & $\begin{array}{r}42 \cdot 5 \\
15 \cdot 6 \\
15 \cdot 3 \\
13.0 \\
8 \cdot 1 \\
5 \cdot 3\end{array}$ \\
\hline & All Ages & $100 \cdot 0$ & $100 \cdot 0$ & $100 \cdot 0$ & $100 \cdot 0$ \\
\hline
\end{tabular}

Table II gives the computed cancer death rates, and obviously their reliability will depend

TABLE II

CANCER MORTALITY IN PARSIS AND THE REST

\begin{tabular}{|c|c|c|c|c|c|c|c|c|c|c|c|}
\hline \multirow[t]{2}{*}{ Population } & \multirow[t]{2}{*}{ Age (yrs) } & \multicolumn{2}{|c|}{ Population (estimated) } & \multicolumn{2}{|c|}{$\begin{array}{c}\text { Total Cancer } \\
\text { Deaths } \\
\text { (2 yrs) }\end{array}$} & \multicolumn{2}{|c|}{$\begin{array}{c}\text { Lung Cancer } \\
\text { Deaths } \\
\text { (2 yrs) }\end{array}$} & \multicolumn{2}{|c|}{$\begin{array}{c}\text { Age Specific } \\
\text { Cancer Death } \\
\text { Rates (2 yrs) } \\
\text { per } 100,000 \\
\text { Population }\end{array}$} & \multicolumn{2}{|c|}{$\begin{array}{l}\text { Lung Cancer as } \\
\text { Percentage of } \\
\text { All Cancer } \\
\text { Deaths }\end{array}$} \\
\hline & & Male & Female & Male & Female & Male & Female & Male & Female & Male & Female \\
\hline \multirow[t]{2}{*}{ The Rest } & $\begin{array}{l}<30 \\
30- \\
40- \\
50- \\
60- \\
70+\end{array}$ & $\begin{array}{r}1,345,572 \\
424,921 \\
238,802 \\
120,333 \\
39,109 \\
12,254\end{array}$ & $\begin{array}{r}911,315 \\
184,952 \\
111,390 \\
62,678 \\
34,631 \\
14,043\end{array}$ & $\begin{array}{r}25 \\
73 \\
185 \\
313 \\
287 \\
124\end{array}$ & $\begin{array}{r}20 \\
59 \\
103 \\
147 \\
108 \\
82\end{array}$ & $\begin{array}{r}79 \\
22 \\
45 \\
31 \\
19\end{array}$ & $\begin{array}{l}7 \\
2 \\
7 \\
6 \\
3\end{array}$ & $\begin{array}{r}1 \cdot 9 \\
17 \cdot 2 \\
77 \cdot 5 \\
260 \cdot 1 \\
733 \cdot 8 \\
1,011 \cdot 9\end{array}$ & $\begin{array}{r}2 \cdot 2 \\
31.9 \\
92 \cdot 5 \\
234.5 \\
311.9 \\
583.9\end{array}$ & $\begin{array}{l}1 \overline{12 \cdot 3} \\
11 \cdot 9 \\
14 \cdot 4 \\
10 \cdot 8 \\
15 \cdot 3\end{array}$ & $\begin{array}{l}= \\
\overline{1.9} \\
4.8 \\
5.6 \\
3.7\end{array}$ \\
\hline & All Ages & $2,180,991$ & $1,319,009$ & 1,007 & 519 & 126 & 18 & $46 \cdot 2$ & $39 \cdot 3$ & $12 \cdot 5$ & $3 \cdot 5$ \\
\hline \multirow{4}{*}{ Parsis } & \multirow[b]{3}{*}{$\begin{array}{l}<30 \\
30- \\
40- \\
50- \\
60- \\
70+\end{array}$} & \multirow[b]{3}{*}{$\begin{array}{r}14,889 \\
5,478 \\
5,369 \\
4,560 \\
2,835 \\
1,869\end{array}$} & \multirow[b]{3}{*}{$\begin{array}{r}14,889 \\
5,478 \\
5,369 \\
4,560 \\
2,835 \\
1,869\end{array}$} & \multirow[b]{3}{*}{$\begin{array}{l}\frac{2}{3} \\
10 \\
17 \\
31\end{array}$} & \multirow[b]{3}{*}{$\begin{array}{r}7 \\
10 \\
15 \\
22 \\
27\end{array}$} & \multirow[b]{3}{*}{$\begin{array}{l}\bar{z} \\
\frac{1}{1}\end{array}$} & \multirow[b]{3}{*}{$\frac{\overline{1}}{\frac{1}{1}}$} & \multicolumn{4}{|c|}{ Expected Deaths at Non-Parsi Rates } \\
\hline & & & & & & & & \multicolumn{2}{|c|}{ Cancer (All Sites) } & \multicolumn{2}{|c|}{ Lung Cancer } \\
\hline & & & & & & & & $\begin{array}{r}0 \cdot 3 \\
0.9 \\
4 \cdot 2 \\
11.9 \\
20 \cdot 8 \\
18.9\end{array}$ & $\begin{array}{r}0.3 \\
1.7 \\
5.0 \\
10.7 \\
8 \cdot 8 \\
10.9\end{array}$ & $\begin{array}{l}\overline{0.1} \\
0.5 \\
1.7 \\
2 \cdot 3 \\
2.9\end{array}$ & $\begin{array}{l}\bar{Z} \\
0 \cdot 1 \\
0 \cdot 5 \\
0.5 \\
0.4\end{array}$ \\
\hline & All Ages & 35,000 & 35,000 & 63 & 76 & 2 & 2 & $57 \cdot 0$ & $37 \cdot 4$ & $7 \cdot 5$ & 1.5 \\
\hline
\end{tabular}


upon the validity of the above assumptions regarding age distributions. When the cancer death rates were standardized with respect to the Parsi age distribution for males and females separately, the following rates were obtained:

\begin{tabular}{c|c|c}
\hline Sex & Parsis & The Rest \\
\hline Male & 90 & 81 \\
Female & 109 & 53 \\
\hline
\end{tabular}

It is seen that on standardization the differences in the cancer death rate among Parsis and the rest largely disappeared in the case of males and was substantially reduced in the case of females, so that the relative risk of cancer mortality among Parsi females which appeared to be over five times that obtaining among the rest was reduced to about twice. Thus it is clear that most of the difference between Parsis and the rest in respect of the crude cancer death rate among males is a reflection of the difference in the age structure of the two groups. It is because relatively more of the Parsis reach the ages in which cancer is most prevalent that relatively more of them die from cancer.

Table II also shows the expected number of deaths from cancer (all sites) and cancer of the lung among Parsis, if their age-specific rates had been similar to that of the rest. Strikingly enough, $7 \cdot 5$ lung cancer deaths among Parsi males were expected whereas in fact there have been only two.

As the level of total cancer mortality among females is very different in Parsis and the rest, a direct comparison of the lung cancer mortality in the two categories is not justifiable. Hence, a better index for comparison, which can be used for both males and females, is the number of lung cancer deaths as a percentage of all cancer deaths. Table II shows that, among the rest, this percentage does not vary appreciably with age, so that this index can be used without adjustment for the difference in the age distribution.

The deaths from lung cancer as a percentage of all cancer deaths according to sex and religious faith, both una djusted and adjusted for age, are given in Table III. The adjustment is that of standardization with respect to the Parsi age distribution. It is seen that the percentage does not vary appreciably among females, in Parsis and the rest, and that the slight difference that does appear is not statistically significant. On the other hand, among males this variation in the percentage is statistically significant even at the 1 per cent. level. This relatively low risk among Parsi males of dying from lung cancer is probably related to the fact that on religious grounds they do not smoke.

Also the proportion of lung cancer deaths to all cancer deaths is significantly higher (at the 1 per cent. level) among the rest in males compared with all three other categories combined, which show no significant variations amongst themselves, irrespective of sex and age distributions. The highest proportion of smokers is of course to be found among non-Parsi males, because of the religious taboo on smoking among Parsis, and because smoking among Indian women of all groups is exceedingly rare.

These otservations taken in conjunction are indicative of a causal relationship between the prevalence of smoking and the incidence of lung cancer.

\section{SUMmarY}

(1) In Bombay the Parsis of both sexes appear to have a much higher crude death rate from cancer (all sites) than the rest of the population.

(2) This excess is largely due to the different age distributions of the two groups, the Parsis having a higher proportion of older persons among whom

TABLE III

LUNG CANCER DEATHS AS PERCENTAGE OF ALL CANCER DEATHS AMONG PARSIS AND THE REST, BY SEX

\begin{tabular}{|c|c|c|c|c|c|c|c|c|c|c|c|c|c|}
\hline \multirow{2}{*}{$\frac{\text { Sex } \quad \cdots}{\text { Population }}$} & \multirow{2}{*}{$\cdots$} & \multirow{2}{*}{$\cdots$} & \multirow{2}{*}{$\cdots$} & \multirow{2}{*}{$\cdots$} & \multirow{2}{*}{$\cdots$} & \multicolumn{4}{|c|}{ Male } & \multicolumn{4}{|c|}{ Female } \\
\hline & & & & & & \multicolumn{2}{|c|}{ The Rest } & \multicolumn{2}{|c|}{ Parsis } & \multicolumn{2}{|c|}{ The Rest } & \multicolumn{2}{|c|}{ Parsis } \\
\hline \multicolumn{2}{|c|}{ Site of Cancer } & $\cdots$ & $\cdots$ & $\cdots$ & $\ldots$ & Not Lung & Lung & Not Lung & Lung & Not Lung & Lung & Not Lung & Lung \\
\hline \multicolumn{4}{|c|}{ Number of Cancer Deaths .. } & $\cdots$ & $\cdots$ & 881 & 126 & 61 & 2 & 501 & 18 & 74 & 2 \\
\hline \multicolumn{6}{|c|}{$\begin{array}{l}\text { Lung Cancer Deaths as Percentage of All } \\
\text { Cancer Deaths (unadjusted) } \\
\end{array}$} & \multicolumn{2}{|c|}{$12 \cdot 5$} & \multicolumn{2}{|c|}{$3 \cdot 2$} & \multicolumn{2}{|c|}{$3 \cdot 5$} & \multicolumn{2}{|c|}{$2 \cdot 6$} \\
\hline \multicolumn{6}{|c|}{$\begin{array}{l}\text { Lung Cancer Deaths as Percentage of All } \\
\text { Cancer Deaths (adjusted for age) }\end{array}$} & \multicolumn{2}{|c|}{$13 \cdot 2$} & \multicolumn{2}{|c|}{$3 \cdot 2$} & \multicolumn{2}{|c|}{$4 \cdot 0$} & \multicolumn{2}{|c|}{$2 \cdot 6$} \\
\hline
\end{tabular}


cancer mortality is high. Standardization by age shows that for males the mortality risk for Parsis and "the rest" are nearly equivalent; for females, the risk for Parsis is reduced from over five times to about twice that in "the rest".

(3) The proportion of lung cancer to all cancer deaths in males is significantly lower for Parsis than for the rest, but in females there is no such significant difference between Parsis and the rest. This relatively low risk among Parsi males of dying from lung cancer is possibly related to the fact that, on religious grounds, members of this community do not smoke.

(4) The proportion of lung cancer to all cancer deaths is significantly higher among males in "the rest" than among the other three "non-smoking" categories (Parsi males, Parsi females, and all other females) combined, which amongst themselves do not vary significantly. This indicates a causal relationship between the prevalence of smoking habit and the incidence of lung cancer.

I am deeply indebted to Professor F. A. E. Crew for his interest, encouragement, and advice. My thanks are also due to Dr. V. N. Panse of the Department of Preventive and Social Medicine for his numerous useful suggestions, to the Executive Health Officer, Bombay Municipal Corporation, for permission to examine the death records, to Dr. D. V. Parulekar for making available the necessary facilities, and to Dr. K. K. Soman for his help in abstracting the data.

\section{REFERENCES}

Bombay, Government of (1952). "Greater Bombay District Census Handbook (Based on the 1951 Census)". Bombay.

Handbook (Based on the 1951 Census)". Bombay.
Bombay Municipal Corporation (1958). "Annual Report of the Executive Health Officer for 1957". Municipal Printing Press,
Eunicipal Corporation (1958). "Annual Report of the Bombay.

- (1959). "Annual Report of the Executive Health Officer for 1958". Municipal Printing Press, Bombay.

Chandra Sekar, C. (1948). "Some Aspects of Parsi Demography". John Hopkins Press, U.S.A. 